\title{
Time-resolved fluorescence spectra of untreated and sodium borohydride reduced chromophoric dissolved organic matter
}

Yuan Chen, ${ }^{q,}$ Juan Liu, ${ }^{q,}$ Xu Zhang, ${ }^{, \neq}$Neil V Blough ${ }^{\S}$

${ }^{\ddagger}$ Department of Environmental Science, School of Resources and Environmental Science,

Wuhan University, Wuhan, 430079, P.R. China

§Department of Chemistry and Biochemistry, University of Maryland, College Park, Maryland 20742, United States

*Corresponding Author

Supporting Information Pages: 10

Supporting Information Figures: 8

Supporting Information Tables: 1 
Table S1 emission quantum yield ( $\phi$ ) for untreated CDOM and $\mathrm{NaBH}_{4}$ reduced CDOM (Red-CDOM) excited at 375 and $440 \mathrm{~nm}$.

\begin{tabular}{ccccccccc}
\hline Excitation & SRNOM & $\begin{array}{c}\text { Red- } \\
\text { SRNOM }\end{array}$ & SRHA & $\begin{array}{c}\text { Red- } \\
\text { SRHA }\end{array}$ & ESHA & $\begin{array}{c}\text { Red- } \\
\text { ESHA }\end{array}$ & PPHA & $\begin{array}{c}\text { Red- } \\
\text { PPHA }\end{array}$ \\
\hline $375 \mathrm{~nm}$ & $7.4 \mathrm{E}-3$ & $2.2 \mathrm{E}-2$ & $2.6 \mathrm{E}-3$ & $7.7 \mathrm{E}-3$ & $3.3 \mathrm{E}-3$ & $8.7 \mathrm{E}-3$ & $2.7 \mathrm{E}-3$ & $8.9 \mathrm{E}-3$ \\
$440 \mathrm{~nm}$ & $6.4 \mathrm{E}-3$ & $2.2 \mathrm{E}-2$ & $3.0 \mathrm{E}-3$ & $9.2 \mathrm{E}-3$ & $4.4 \mathrm{E}-3$ & $9.1 \mathrm{E}-3$ & $4.0 \mathrm{E}-3$ & $1.1 \mathrm{E}-2$ \\
\hline
\end{tabular}




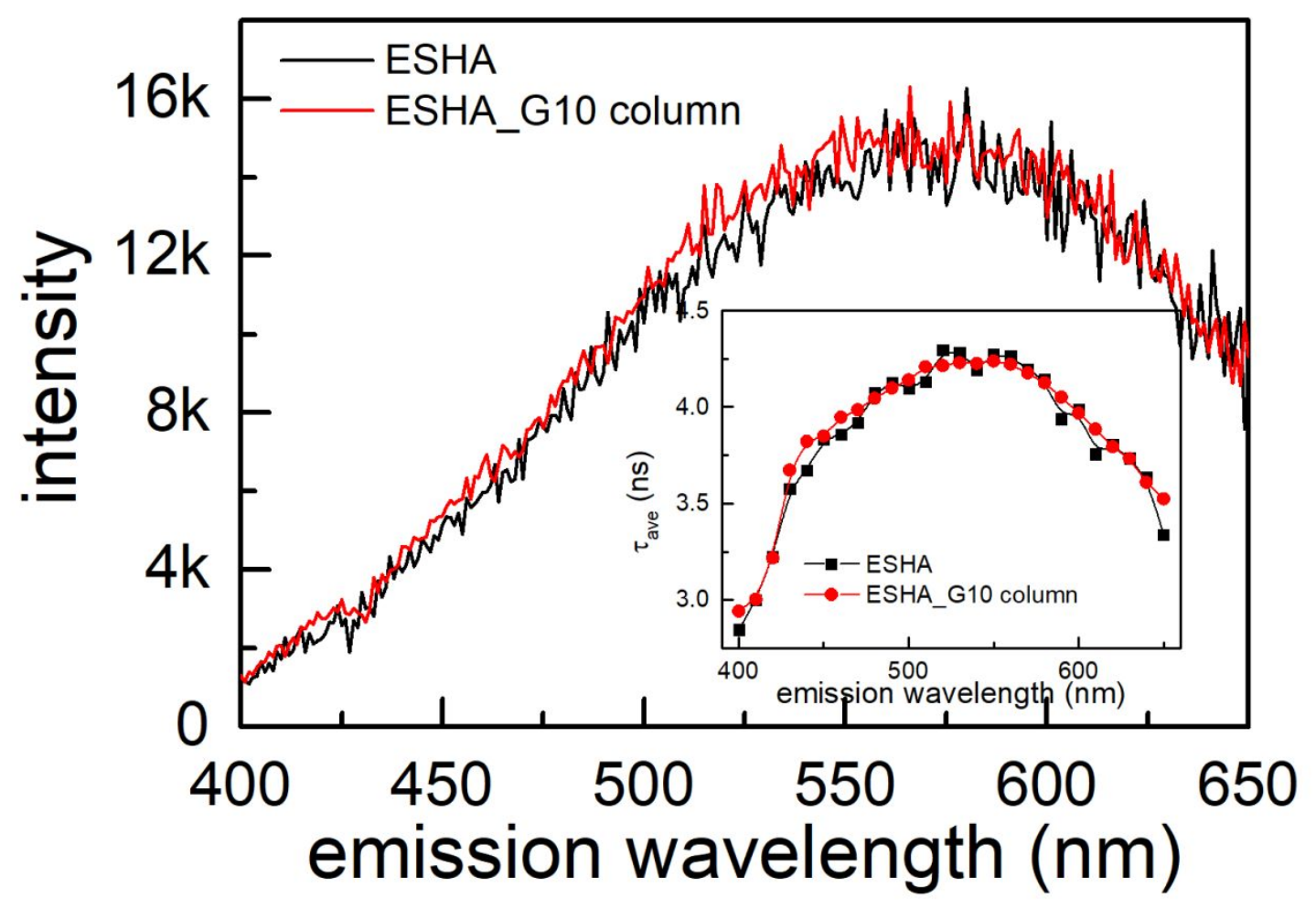

Figure S1. Effect of G 10 column treatment on the steady-state and intensity-weighted average lifetime of ESHA. 

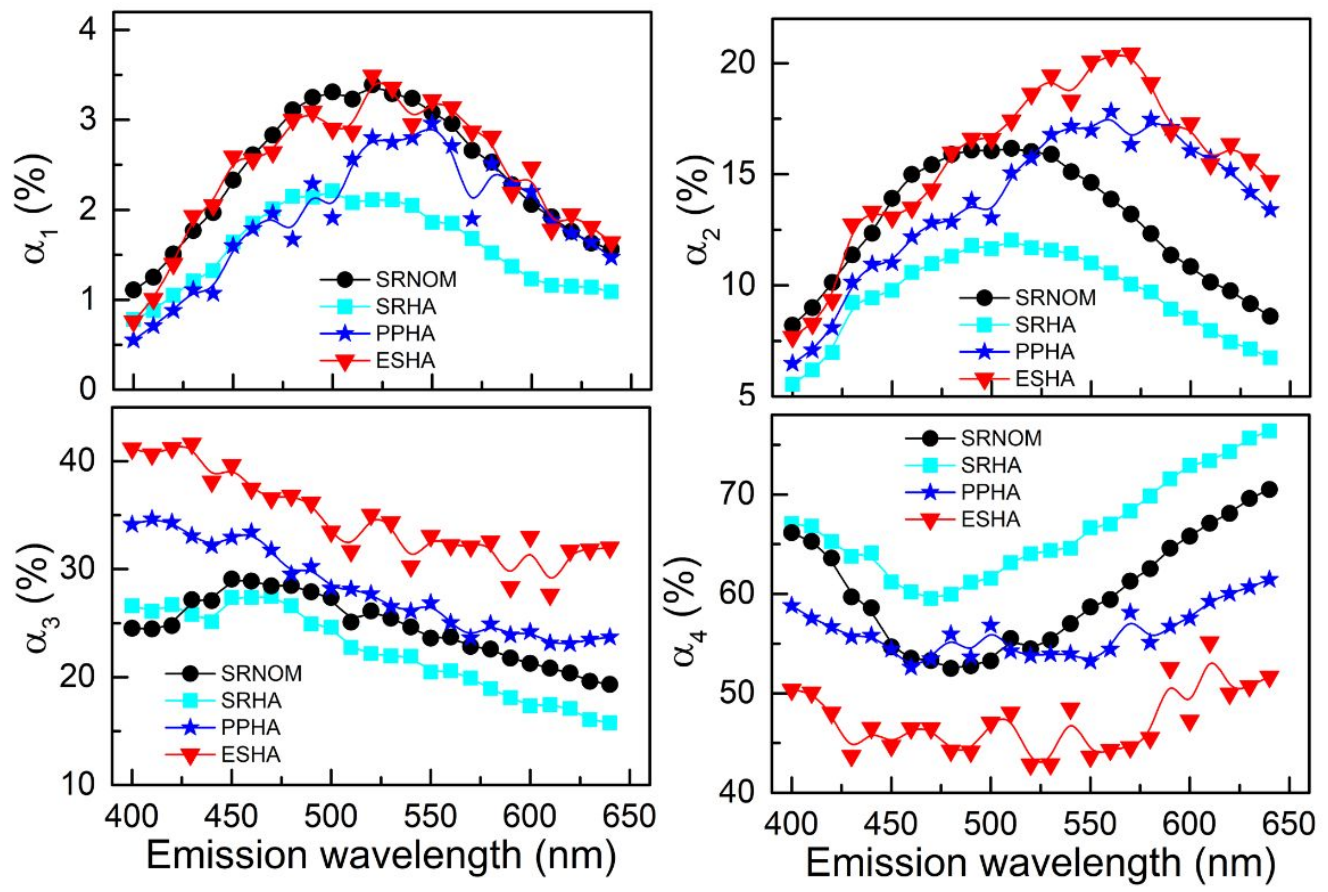

Figure S2. Component amplitude $\left(\alpha_{i}\right)$ for each $\tau_{i}$ recovered from exponential decovolotion of emission decay recorded on the PMA 175 detector at excitation of 375 nm. 

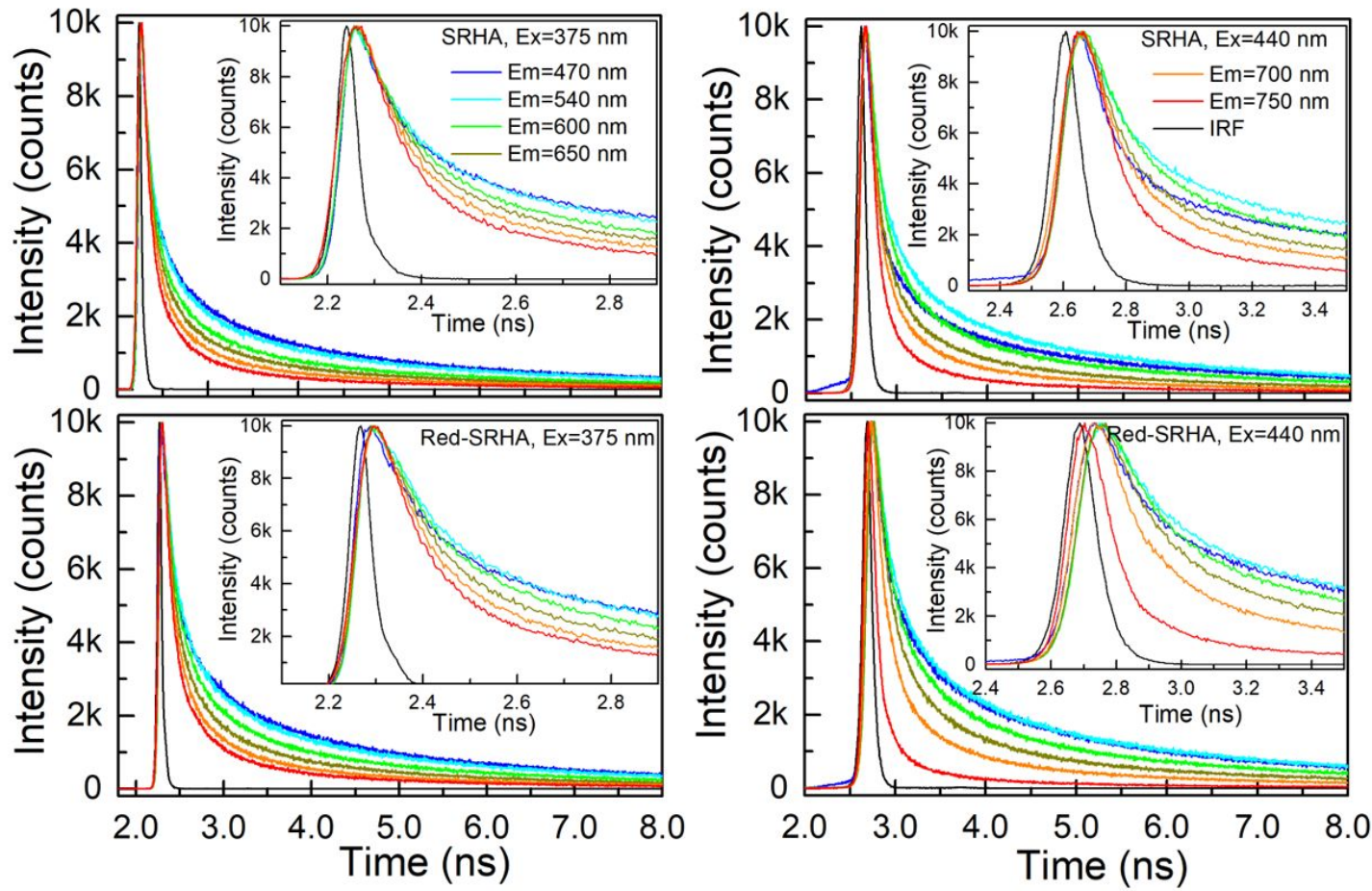

Figure S3. Emission decays $(\mathrm{Em}=470,540,600,650,700$, and $750 \mathrm{~nm})$ of untreated SRHA and $\mathrm{NaBH}_{4}$ reduced SRHA (red-SRHA) that recorded using a PMA hybrid 07 detector under excitation of 375 and $440 \mathrm{~nm}$, inset showed the amplified decay region. 

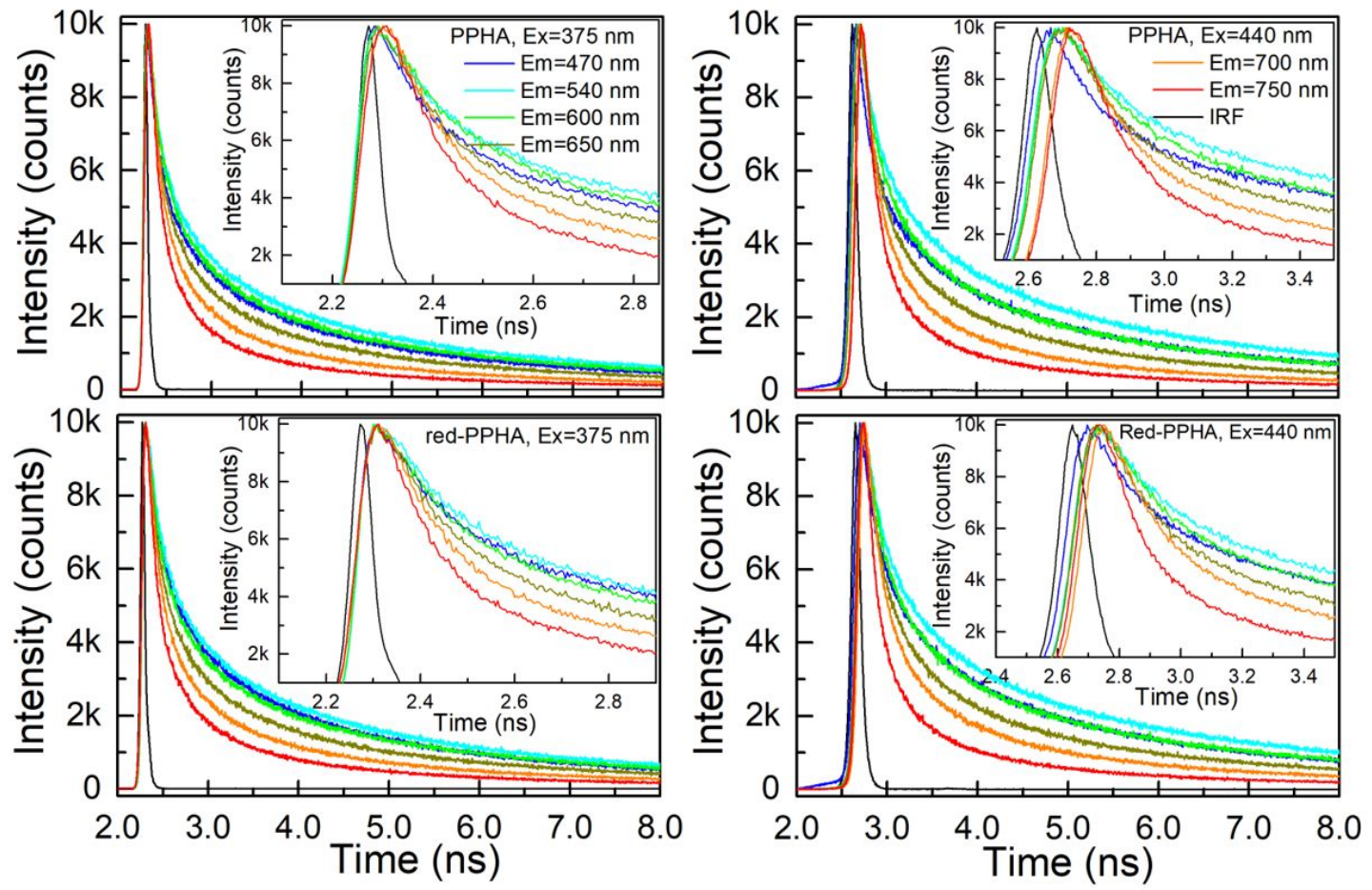

Figure S4. Emission decays $(\mathrm{Em}=470,540,600,650,700$, and $750 \mathrm{~nm})$ of untreated SRHA and $\mathrm{NaBH}_{4}$ reduced PPHA (red-PPHA) that recorded using a PMA hybrid 07 detector under excitation of 375 and $440 \mathrm{~nm}$, inset showed the amplified decay region. 

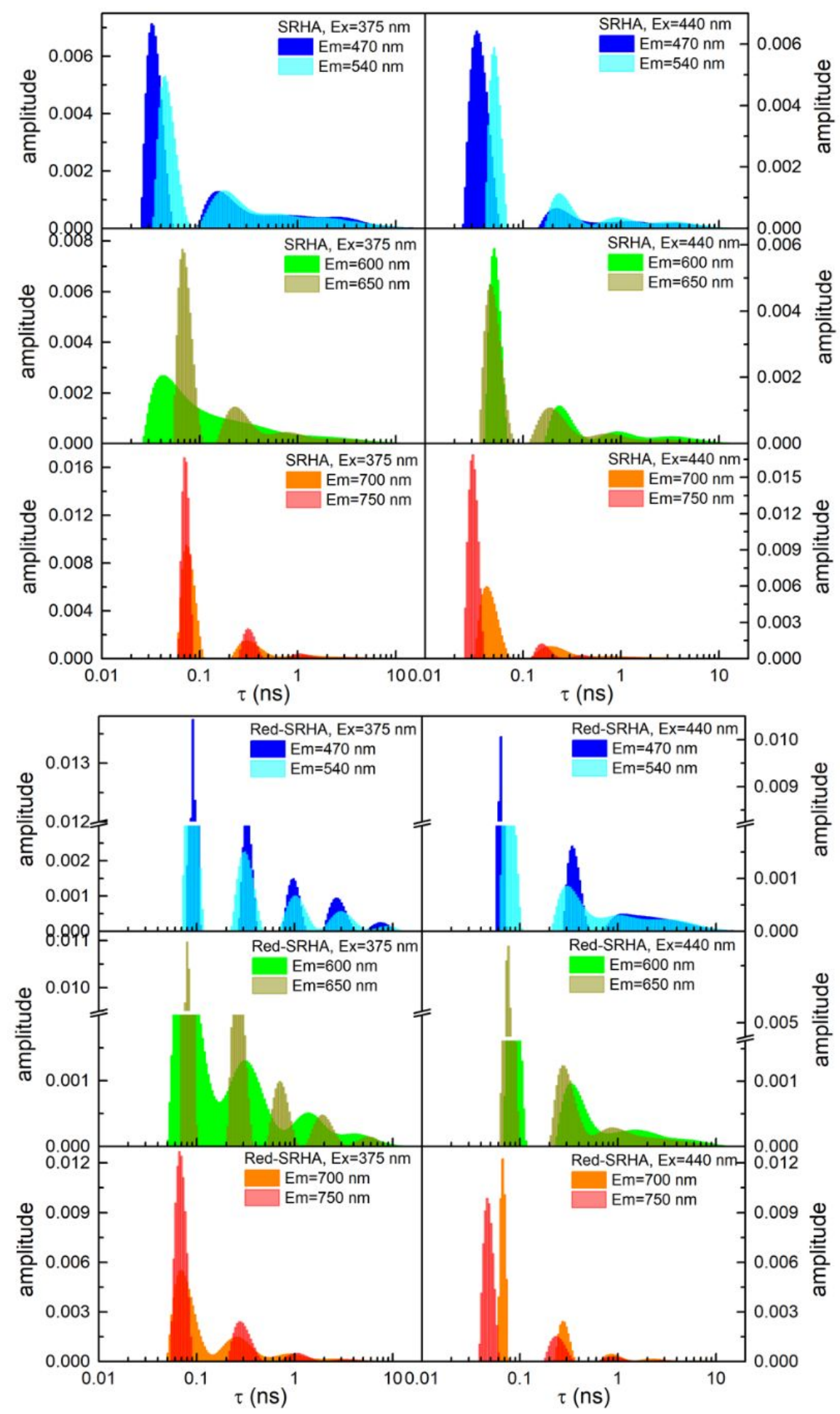

Figure S5. Fluorescence lifetime distribution of untreated SRHA and $\mathrm{NaBH}_{4}$ reduced SRHA (Red-SRHA) that recorded using a PMA hybrid 07 detector under excitation of 375 and $440 \mathrm{~nm}$. 

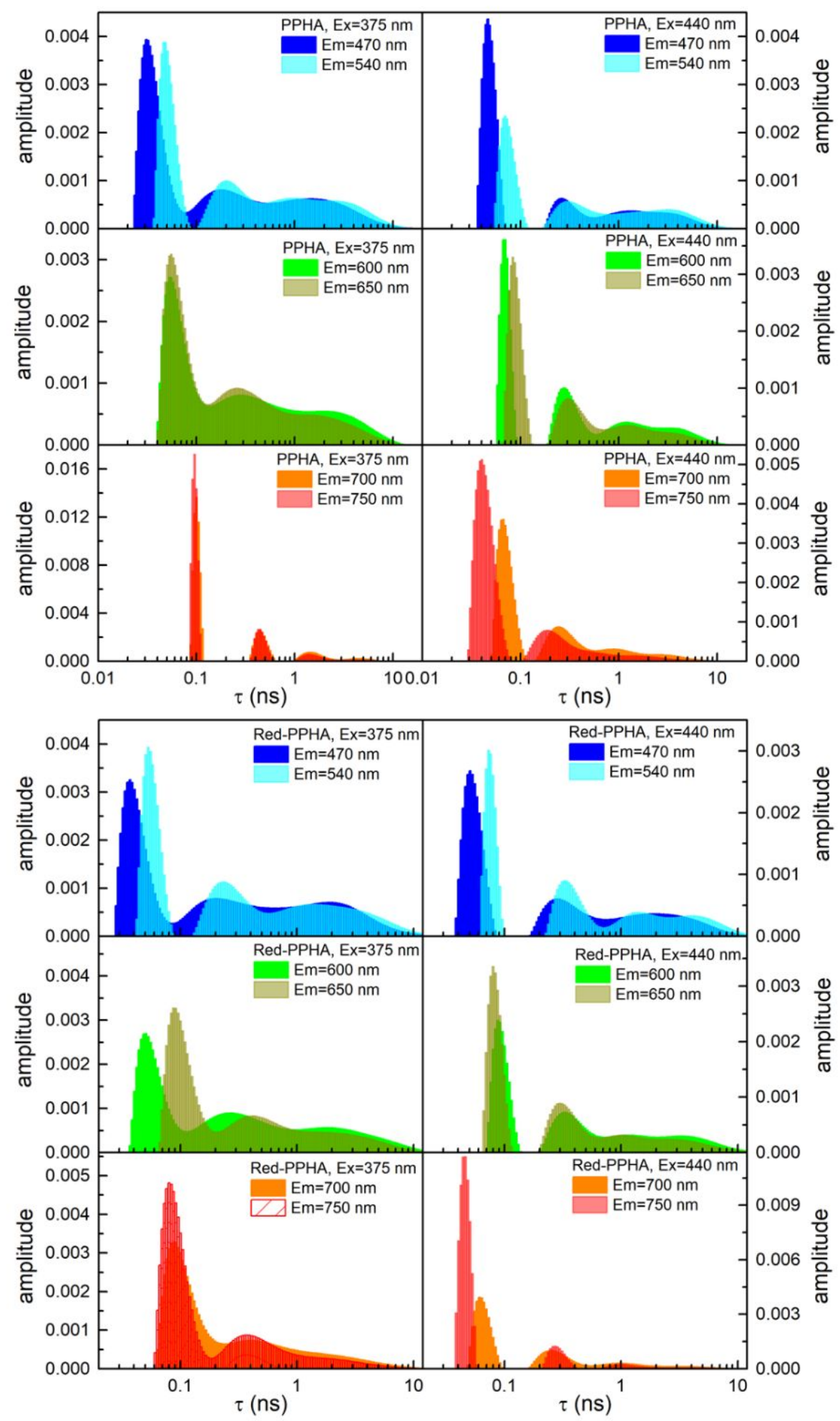

Figure S6. Fluorescence lifetime distribution of untreated $\mathrm{PPHA}$ and $\mathrm{NaBH}_{4}$ reduced PPHA (Red-PPHA) that recorded using a PMA hybrid 07 detector under excitation of 375 and $440 \mathrm{~nm}$. 

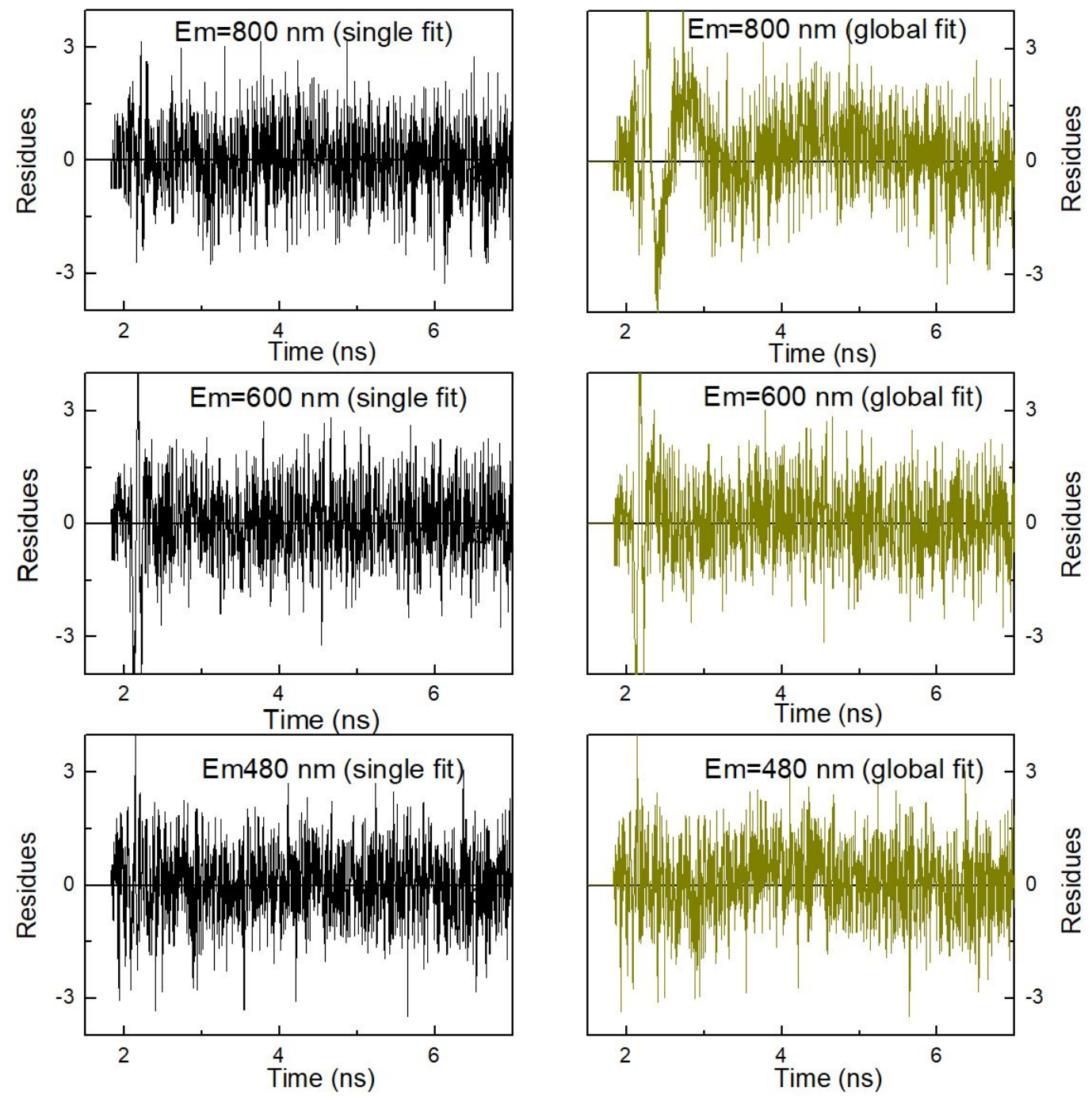

Figure S7. Residuals between the multi-exponential fit (left panel) and global fit (right panel) of a sum of four discrete components and measured emission decay of ESHA at 800,600 , and $480 \mathrm{~nm}$.

As shown in Figure S7, residuals for the global exponential fit was oscillation, particulaly at the bule and red edge where short-lived species dominates. Conversely, residuals for multi-expenential fit without linking fluorescence lifetime was random. Notably, the residuals were comparable at emission of $600 \mathrm{~nm}$, where long lived speies dominate. 


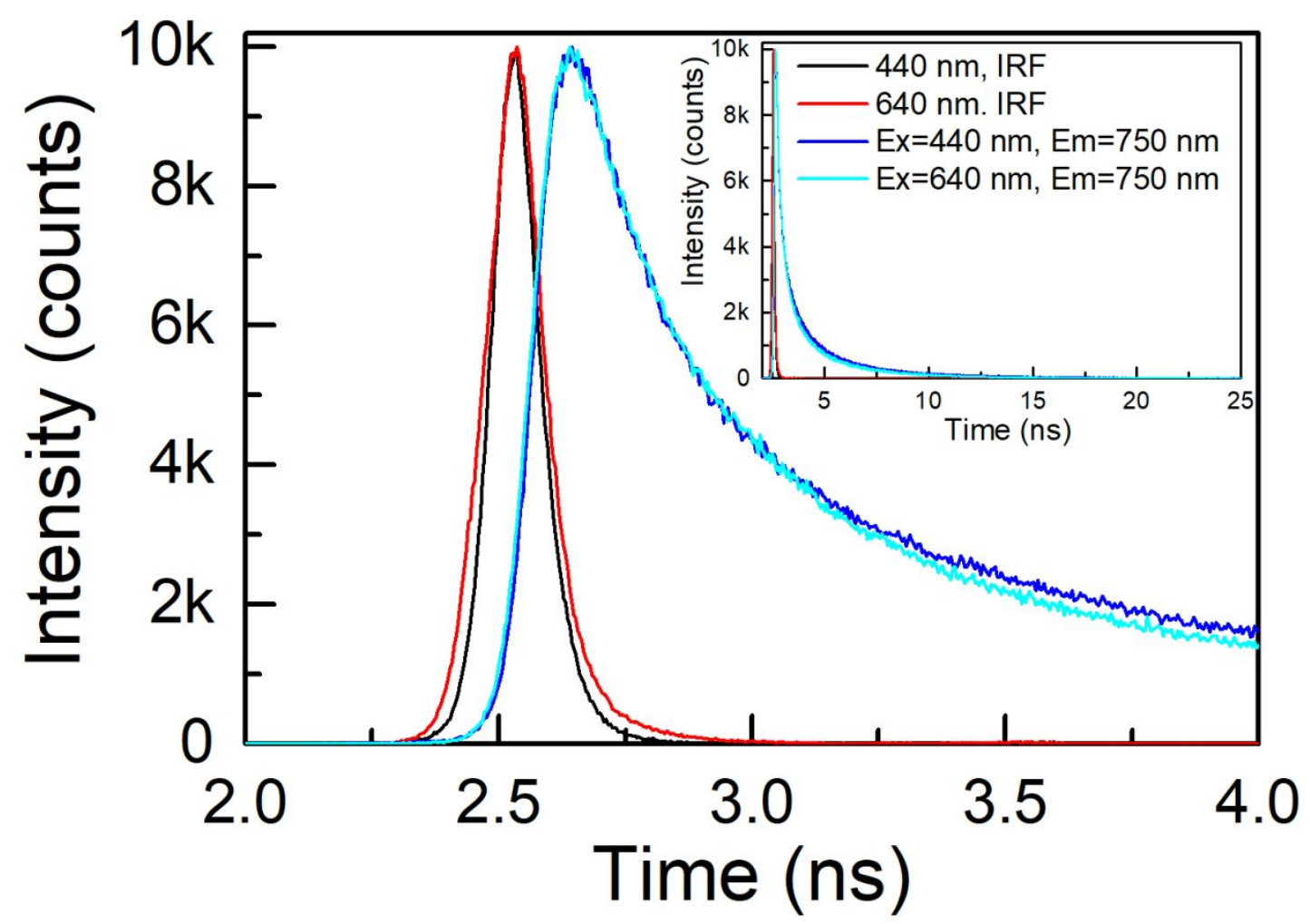

Figure S8. IRF for excitaiton of $440 \mathrm{~nm}$ and $640 \mathrm{~nm}$, and the typical emission decay at $750 \mathrm{~nm}$, inset showed the decay in long time scale. 